\title{
MULTIRESOLUTION ANALYSIS IN THE VISIBLE SPECTRUM OF LANDSAT-TM IMAGES THROUGH WAVELET TRANSFORM
}

\author{
Marilyn CEPEDA ${ }^{1}$, Iván PALACIOS ${ }^{1}$, Alfonso TIERRA ${ }^{2}$, Eduardo KIRBY $^{2}$
}

DOI: 10.21163/GT_2018.131.03

\begin{abstract}
:
Multispectral satellite images are tools that allow the analysis of phenomena developed on the Earth's surface without being in contact. It is a raster model so it is possible to decompose it into a digital signal. There is a certain data that presents alterations (noise) due to errors caused by the sensors, atmospheric conditions, among others. Such examples affect its use and its derived products. Satellite images by their nature present difficulty in their processing and handling due to the considerable weight they have; whose problem justified the present work. The objective is to minimize white noise and to compress the image with the least possible loss of information through the Multiresolution Analysis (MRA) technique and Wavelet transformation. The images worked belong to the National Recreation Area "El Boliche" (Ecuador) that is next to the Cotopaxi volcano. Through a standard deviation evaluation of the obtained wavelet coefficients, the order of the "Discrete Wavelet Transform" (DWT) was established in the Daubechies (db) and Haar families. With db3 level 4, obtained a compression of $11.268 \%$ in respect to the original weight and with Haar level $411.288 \%$ as the best results. The wavelet $\mathrm{db}$ is more effective than the Haar type for the treatment of multispectral satellite images in the elimination of white noise and compression by means of the MRA, with a reconstruction of the signal without loss of information due to the type of wavelet used, which is evidenced in the image.

Key-words: wavelets, MRA, satellite image, noise, compression.
\end{abstract}

\section{INTRODUCTION}

Satellite technologies depend on using electromagnetic energy and its products such as satellite images or Global Positioning Systems depend on the wavelengths which are not equally effective for all remote sensing applications (González, 2014; Eastman, 2001; Tierra, 2016; Haidu, 2016). The images are captured by sensors; however, often present some type of distortion or redundancy in the data known. This distortion is known as noise which is stochastic variations that "contaminate an image" (Villegas, Puetamán \& Salazar, 2007). Noise is produced by factors such as: atmospheric effects (selective and nonselective dispersion) and by the blur of the sensor, which limits its use (Fournier et al., 1997; Ergen, 2012). According to Miano (1999), and Chambolle et al., (1998) elimination of noise, as well as the compression of images are required to digital signals because problems related to information use and processing.

The wavelet is a technique used in the last decades for noise elimination and images compression. Wavelet has been used in different fields such as in medicine (Dalmiya et al., 2012; Weaver et al., 1991; Paz, 2001), in geology (Mohan \& Poobal, 2017), natural

\footnotetext{
${ }^{1}$ Ingeniería Geográfica y del Medio Ambiente. Universidad de las Fuerzas Armadas ESPE, Av. Gral Rumiñahui. Sangolquí, Ecuador, mvcepedal@espe.edu.ec; ifpalacios@espe.edu.ec

${ }^{2}$ Grupo Geoespacial. Universidad de las Fuerzas Armadas ESPE, Av. Gral Rumiñahui Sangolquí, Ecuador,artierra@espe.edu.ec; epkirby@espe.edu.ec
} 
sciences (Rathinasamy et al., 2017; Bachour et al., 2016) and especially with remote sensors (Pipitone et al., 2018; Ansari \& Buddhhiraju, 2016; Dheepa \& Sukumaran, 2014), among others.

The wavelet technique analyzes image's content in each pixel decomposing the original signal into different scales with different levels of resolution (Eregen, 2012). Each level of resolution carries required information to reconstruct the original signal to the next level (Ballesteros, Renza \& Rincon, 2015). In order to use the Multiresolution Analysis (MRA) we studied mathematical models as a function of signals behavior to reduce nonessential data from the original signal. The wavelet transform allows images processing of with reduced white noise and compression of information (Chambolle et al., 2015).

The objective of this study was to eliminate the white noise and compress a Landsat TM satellite image through the MRA technique and wavelet transform with a comparison between Haar and Daubechies (db) as an alternative for the use of images noise free and storage facility.

\section{METHODS}

\subsection{Landsat TM multispectral images}

Landsat TM is a multispectral scanning sensor created to obtain higher image resolution, its data are sensed in seven spectral bands (Table 1). When these bands are combined, they produce a range of tonalities and interpretations which greatly increase their applications. Depending on the satellite and the sensor, panchromatic and thermal multispectral channels can be included (NASA, 2017).

Characteristics of the Landsat TM sensor

Table 1.

\begin{tabular}{|c|c|}
\hline \multicolumn{2}{|c|}{ TM Technical Specifications } \\
\hline Spatial Resolution & 30 meters \\
\hline Spectral Range & $0.45-12.5 \mu \mathrm{m}$ \\
\hline Number of Bands & 7 \\
\hline Temporal Resolution & 16 days \\
\hline Image Size & $185 \mathrm{~km} \times 172 \mathrm{~km}$ \\
\hline
\end{tabular}

\subsection{Noise}

It is a defect of unwanted information due to data stochasticity which contaminates or degrades its use (Márquez, 2012). In the specific case of images, generally it represents the isolated pixels that take values other than the "real" ones. There are several types of noise in the treatment of signals such as: Gaussian or white that has reserved to the amplitude distribution with a function of normal probabilistic density, Brownian that has a maximum autocorrelation with increasing frequency and Flicker that decreases each time which doubles the frequency (Márquez, 2012). A recorded signal with corrupted noise can be represented as;

$$
g(x, y)=f(x, y)+n(x, y)
$$

Where $g(x, y)$ is the result of the original image distortion $f(x, y)$ by additive Gaussian noise $n(x, y)$. 
The impulsive or Brownian is generated by digital (or even analog) transmission. It can be modeled as:

$$
g(x, y)=(1-p) * f(x, y)+p * i(x, y)
$$

Where $i(x, y)$ is the impulsive noise and $p$ belongs to $\{0,1\}$. The multiplicative or Flicker presents a granular appearance in the radar and ultrasound images. It is represented as:

$$
g(x, y)=f(x, y) * m(x, y)
$$

Where $m(x, y)$ is the multiplicative noise.

The present study focuses on the Gaussian noise which is usually produced by the sensor electronic components (Ballesteros, Renza \& Rincon, 2015). The energy spectrum is constant for all frequencies, affects the entire image and the intensity of all pixels is altered and discontinuous (Villegas, Puetamán \& Salazar, 2007). The final value of the pixel is the real value plus a certain amount of error. This can be described as a Gaussian variable following a normal distribution (Acevedo, 2011).

\subsection{Wavelet transform}

A Wavelet is a small wave whose energy is concentrated in time, its characteristic waveform is oscillating with a rapid attenuation that allows it to make analysis in time and frequency (Nieto \& Orozco, 2008; Ballesteros, Renza \& Rincon, 2015). It is based on the representation of a function in terms of a biparametric family of dilations and translations of a fixed function $\psi$, the mother wavelet is not sinusoidal, and it is represented as:

$$
W T(f(x))=f(x) * \Psi(x)=\frac{1}{a} \int_{-\infty}^{+\infty} f(t) \Psi\left(\frac{x-t}{a}\right) d t
$$

Where "a" is the scale factor (dilation), "t" is the time (translation) and " $\mathrm{x}$ " is the position. The function $\psi$ is called "mother wavelet"; first, wavelet because it is of an oscillating nature and of finite duration (compact support) and it is called mother for serving as the basis for the generation of the remaining window functions (Ballesteros, Renza \& Rincon, 2015)

\subsection{Discrete wavelet transform in 2D}

The Multiresolution Analysis (MRA) method was used to calculate scaling coefficients of the wavelet transform. The data analyzed in the DWT are discrete and not stationary, therefore a methodology that manages to discretize the signals at specific levels is required. Mallat in 1988 proposed an algorithm based on sequence filters to obtain the wavelet transform instantaneously, which was called Mallat tree or decomposition wavelet tree (Mallat, 1989).

The MRA analyzes the content of images at different scales (resolutions) and at each level of resolution. MRA approach and detail signals carry all the information required to reconstruct the signal at the next level (Cadena \& Cadena, 2016; Mallat, 1989). The wavelet coefficients calculation to reconstruction the signal should be performed quickly (Ballesteros, Renza \& Rincon, 2015). High-pass and low-pass filters, which change the signal resolution, are used with high and low frequency components (Villegas, Puetamán \& Salazar, 2007). The scale is changed through upsampling and downsampling (Daubechies, 
1992). The MRA main feature is the ability to separate a signal into many components at different scales (resolutions) (Daubechies, 1992). The Haar system is not very appropriate to approximate soft functions, in fact any approximation of Haar is a discontinuous function (Villegas, Puetamán \& Salazar, 2007).

The Fig.1 shows how the DWT in each step (low and high) divides the image and continues to the next level with a new step and subdivides the signal to meet the level of discretization, which is assigned to the transformation. The result is to obtain the wavelet and scale coefficients in this case it is a level 3 discretization:

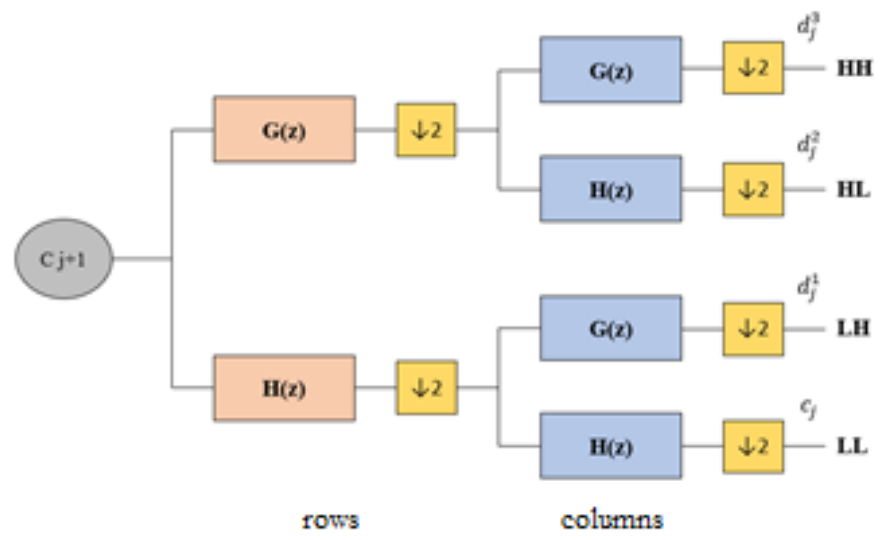

Fig. 1. Decomposition Wavelet tree of images.

Where dj are wavelet coefficients, cj are scaling coefficients that together reconstruct the original signal passing through the high pass filters $\mathrm{G}(\mathrm{z})$ and low pass $\mathrm{H}(\mathrm{z})$ (Pérez et al., 2002). The increase in number of samples $(\uparrow 2)$ is called upsampling and the downsampling $(\downarrow 2)$ removes samples of the signal, thus reducing the sample rate (Kingsbury, 2001; González, 2014; Mancero et al., 2017). The letters HH, HL, LH, LL, represent the filters high - high, high - low, low - high and low - low respectively.

For the selection of a wavelet type, following properties must be considered (Fournier et al., 1997):

Properties that must be considered for the selection of the wavelet

Table 2.

\begin{tabular}{|c|l|}
\hline \multicolumn{2}{|c|}{ Properties } \\
\hline $\begin{array}{c}\text { Compact } \\
\text { support }\end{array}$ & $\begin{array}{l}\text { Filters must be FIR (finite impulse response), which are a } \\
\text { type of digital filters whose response to a pulse input signal } \\
\text { will have a finite number of non-zero terms. }\end{array}$ \\
\hline $\begin{array}{c}\text { Rational } \\
\text { coefficients }\end{array}$ & It avoids floating-point operations \\
\hline $\begin{array}{c}\text { Smoothness } \\
\text { Length of } \\
\text { filters }\end{array}$ & $\begin{array}{l}\text { If the wavelet is not smooth, the error will be easy to detect } \\
\text { visually }\end{array}$ \\
\hline
\end{tabular}


The filters that meet the condition are known as Quadrature Mirror Filters (QMF) González, 2014; Gómez et al., 2013). In multispectral images, the correlations between the bands are considerable, so this technique seeks to reduce spectral, spatial correlation and allow high compression radius (Ballesteros, Renza \& Rincon, 2015). One step produces 4 subpictures or subbands, one is the approximation of the image, and the other 3 capture the vertical, horizontal and diagonal details of the image (Acevedo, 2011). Figure 2 shows the larger sub-bands V1, H1 and D1 which capture the vertical, horizontal and diagonal details on the finer scale, these types of filters are known as Sobel, Roberts, Prewitt filters respectively (Shrivakshan \& Chandrasekar, 2012). The sub-bands V2, H2 and D2 belong to the second fine scale. An approximation of the reconstructed image is the LL band in the upper left corner (Acevedo, 2011).

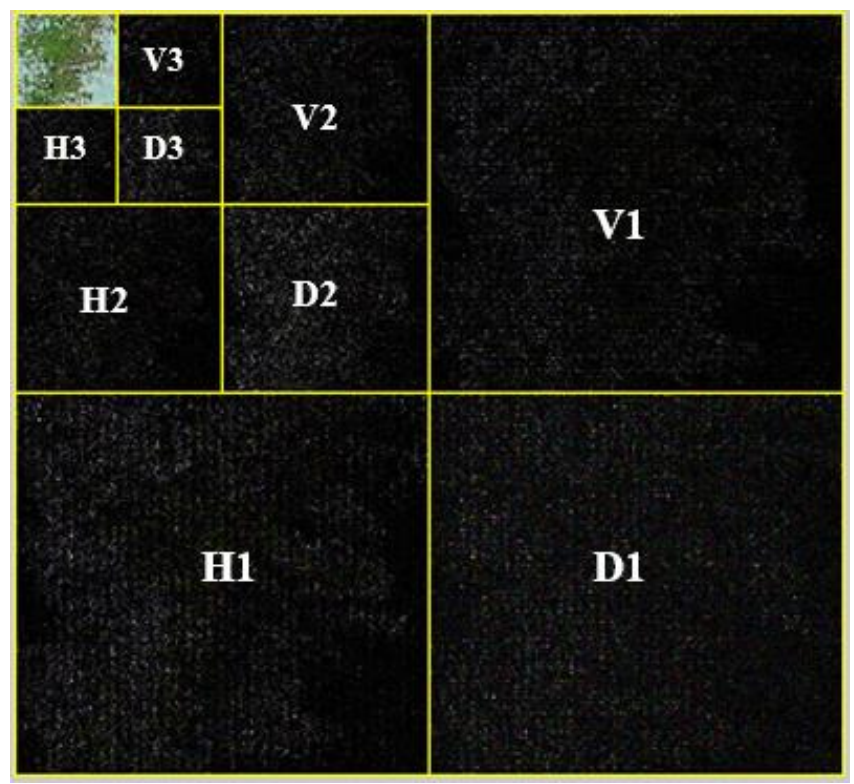

Fig. 2. Discretization of the image.

\section{METHODOLOGY}

The Landsat TM image of the National Recreation Area "El Boliche" - Ecuador was obtained from the official USGS (U.S. Geological Survey) website free of charge. The bands of the visible spectrum red, green and blue (RGB). Bands were separated and analyzed each one using the data and graphs obtained. Up to this moment, Haar approach is widely used in treatment of images as shown in the works of Talukder \& Harada (2007), Porwik \& Lisowska (2004), Raviraj \& Sanavullah (2007) and Lai \& Kuo (2000). In addition, the compression of information is lossy, while with another type of wavelet as db is lossless. For this reason, we decided to compare the results between the two approaches. Throughout an exploratory study of wavelet coefficients standard deviation of the image filtering which were obtained in the MATLAB wavelet toolbox package. Subsequently, the order of the wavelet and its level of discretization were determined according to the variation standard deviation in each level (Table 3). The optimal discretization level was 
order 4 but 2, 3, 5 and 6 orders were worked with discretization levels 2, 3 and 4 for a better appreciation of results.

Standard deviation values for each wavelet order and their levels

Table 3.

\begin{tabular}{|c|c|c|}
\hline Wavelet Type & $\begin{array}{c}\text { Discretization } \\
\text { Level }\end{array}$ & $\begin{array}{c}\text { Standard deviation of the } \\
\text { coefficients of the transform }\end{array}$ \\
\hline \multirow{3}{*}{$\mathrm{db} 2$} & 2 & 2.163 \\
\cline { 2 - 3 } & 3 & 2.350 \\
\cline { 2 - 3 } & 4 & 2.398 \\
\hline \multirow{4}{*}{$\mathrm{db3}$} & 2 & 2.118 \\
\cline { 2 - 3 } & 3 & 2.307 \\
\hline \multirow{4}{*}{$\mathrm{db} 4$} & 4 & 2.356 \\
\cline { 2 - 3 } & 2 & 2.105 \\
\cline { 2 - 3 } & 3 & 2.297 \\
\hline \multirow{4}{*}{$\mathrm{db5}$} & 4 & 2.346 \\
\cline { 2 - 3 } & 2 & 2.103 \\
\cline { 2 - 3 } & 3 & 2.297 \\
\hline \multirow{3}{*}{$\mathrm{db} 6$} & 4 & 2.346 \\
\cline { 2 - 3 } & 2 & 2.105 \\
\cline { 2 - 3 } & 3 & 2.298 \\
\hline & 4 & 2.347 \\
\hline
\end{tabular}

From the MRA, image filtering was performed with $\mathrm{db}$ and Haar wavelets for noise reduction, the statistics and percentage of energy retained were obtained. In the same way, the image was compressed with both wavelets. Once obtained the filtration and compression of the image, we proceeded to program an algorithm in the MATLAB software to graph the reconstructed signal in each band of the image. The best results were established for the elimination and compression.

\section{RESULTS AND DISCUSSION}

There is presence of noise in the Landsat TM images, determined by the visual analysis of the peaks in the signal expressed in digital levels values of each of the three bands of the visible spectrum (RGB). From the results of Table 3, it was determined that the standard deviation of the wavelet coefficients does not vary significantly from level 4 , for this reason this level was chosen as the basis for the elimination and compression of the two wavelet families studied.

\subsection{Noise filtering}

The values of the wavelet coefficients were determined for $\mathrm{db} 4, \mathrm{db} 3$ and Haar with level of discretization 4 after filtering the image. The signal with $\mathrm{db}$ had a better reconstruction, due to the proximity to the original value of the frequency of the image in 
the red and blue bands, unlike the green band that obtained a better approximation with Haar (Table 4, 5 and 6).

Comparison of frequency values in the red band

\begin{tabular}{|c|c|c|}
\hline \multicolumn{3}{|c|}{ Red Band } \\
\hline Filtered & Digital level & $\begin{array}{c}\text { Frequency value } \\
(\mathbf{H z})\end{array}$ \\
\hline db3_4 & & $2.370 \mathrm{E}+05$ \\
\hline db4_4 & \multirow{3}{*}{85} & $2.366 \mathrm{E}+05$ \\
\hline haar_4 & & $2.367 \mathrm{E}+05$ \\
\hline Original image & & $2.320 \mathrm{E}+05$ \\
\cline { 1 - 1 } & &
\end{tabular}

Table 4.

Table 5.

Comparison of frequency values in the green band

\begin{tabular}{|c|c|c|}
\hline \multicolumn{3}{|c|}{ Green Band } \\
\hline \multirow{2}{*}{ Filtered } & \multirow{2}{*}{ Digital level } & $\begin{array}{c}\text { Frequency value } \\
(\mathbf{H z})\end{array}$ \\
\hline db3_4 & & $1.766 \mathrm{E}+05$ \\
\hline db4_4 & \multirow{2}{*}{189} & $1.771 \mathrm{E}+05$ \\
\hline haar_4 & & $1.788 \mathrm{E}+05$ \\
\cline { 1 - 1 } Original image & & $1.781 \mathrm{E}+05$ \\
\hline
\end{tabular}

Table 6.

Comparison of frequency values in the blue band

\begin{tabular}{|c|c|c|}
\hline \multicolumn{3}{|c|}{ Blue Band } \\
\hline \multirow{2}{*}{ Filtered } & Digital level & $\begin{array}{c}\text { Frequency value } \\
(\mathbf{H z})\end{array}$ \\
\hline db3_4 & \multirow{3}{*}{85} & $5.623 \mathrm{E}+05$ \\
\hline db4_4 & & $5.632 \mathrm{E}+05$ \\
\hline haar_4 & & $5.405 \mathrm{E}+05$ \\
\hline Original image & & $5.840 \mathrm{E}+05$ \\
\hline
\end{tabular}

This is shown in signal obtained representation for each band in Fig. 3, 4 and 5, in which the 3 bands are represented separately with their frequency value and the digital level, where the noise removal is visually observed but also a notion of the loss of information that is obviously greater in Haar 4.

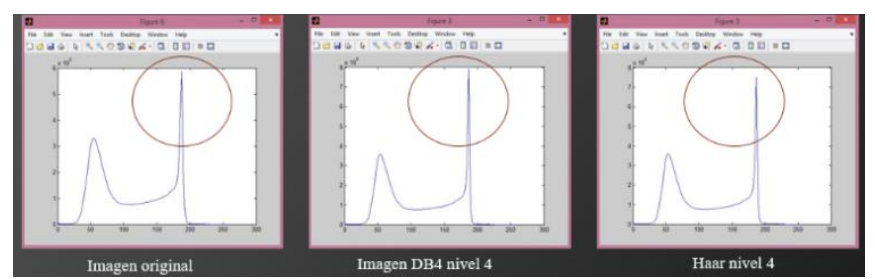

Fig. 3. Reconstructed signal of the blue band 


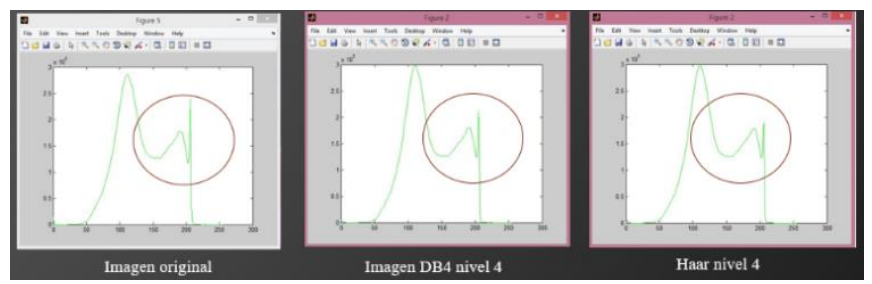

Fig. 4. Reconstructed signal of the green band

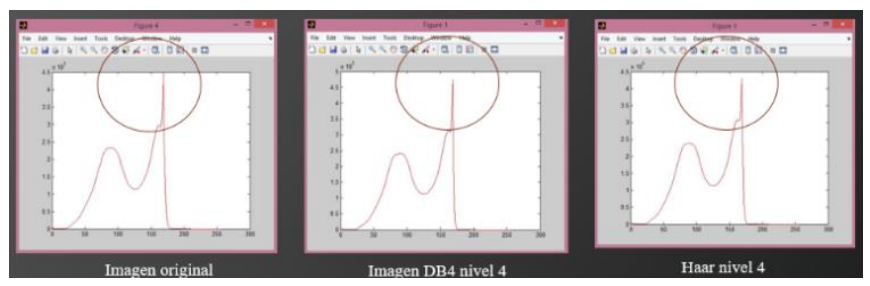

Fig. 5. Reconstructed signal of the red band

\subsection{Compression}

The maximum compressions were: Haar level 4 with $11,288 \%$ and db3 level of discretization 4 with $11,286 \%$ respect to the original weight. The compression had a minimum difference of $0.002 \%$ between Haar and db transforms. The percentage of energy retained for Haar 4 was $99.31 \%$ and for db3 level 4 it was $99.41 \%$, which showed a better reconstruction of the image with the last transform. The filtered and compressed image with db3 discretization level 4 presented better spatial resolution than the image treated with Haar 4, because it had higher percentage of energy retained as evidenced in Fig. 6.

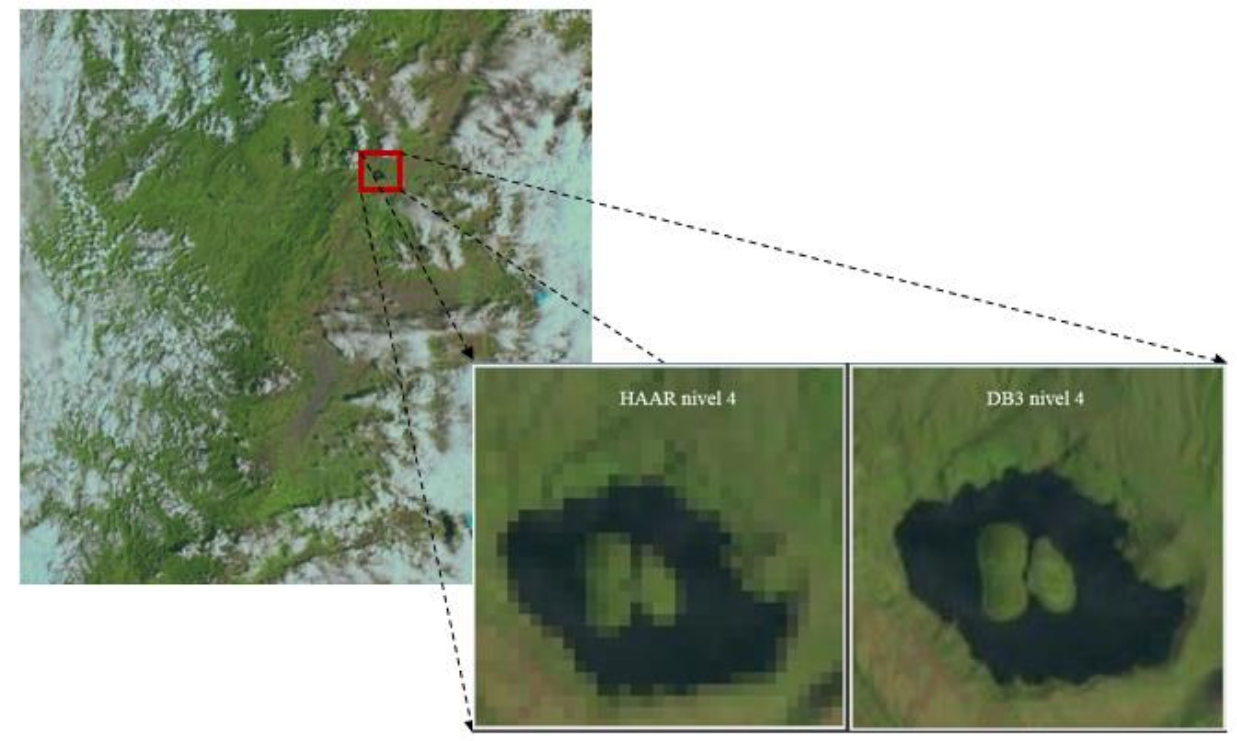

Fig. 6. Visual comparison between filtered and compressed images with Haar 4 and db3 level 4. 


\section{CONCLUSIONS}

The level of discretization 4 was chosen as a basis for filtering and compression because from this level the standard deviation of the coefficients of the transform remained constant with respect to higher levels of discretization. The Landsat-TM images of the area of the National Recreation Area "El Boliche" - Ecuador, presented noise, evidenced visually in the "peaks" of the signals of the RGB spectral bands, which were diminished after the application of the transforms. The best result was obtained with db3 level of discretization 4, for noise filtering due to having a greater percentage of retained energy and for compression to be reduced by $11.286 \%$ in weight with respect to the original image without loss of information. The highest compression was with Haar 4 with $11.288 \%$ (minimum difference of $0.002 \%$ between Haar and db3 level 4), however, the spatial resolution with the Haar wavelet is low compared to the results with db3 level 4 . The filtering and compression with db3 discretization level 4 is better for use in remote sensors, for conserving a radiometric resolution similar to the original and good spatial resolution.

\section{R E F E R E N C E S}

Ansari, R.A. \& Buddhiraju, K.M. (2015). k-means based hybrid wavelet and curvelet transform approach for denoising of remotely sensed images. Remote Sensing Letters, 6(12), 982-991.

Ansari, R.A. \& Buddhiraju, K.M. (2016). A Comparative Evaluation of Denoising of Remotely Sensed Images Using Wavelet, Curvelet and Contourlet Transforms. Journal of the Indian Society of Remote Sensing, 44(6), 843-853.

Bachour, R., Maslova, I., Ticlavilca, A.M., Walker, W.R. \& McKee, M. (2016). Wavelet-multivariate relevance vector machine hybrid model for forecasting daily evapotranspiration. Stochastic Environmental Research and Risk Assessment, 30(1), 103-117.

Ballesteros, D.M., Renza, D. \& Rincon, R. (2015). Gray-scale Images within Color Images using Similarity Histogram-Based Selection and Replacement Algorithm. Journal Of Information Hiding And Multimedia Signal Processing, 6, 1156-1166

Cadena, L. \& Cadena, F. (2016). Análisis multiresolución en el procesamiento de imágenes satelitales. Revista GEOESPACIAL, 115-126.

Chambolle, A., De Vore, R.A., Lee, N.Y. \& Lucier, B.J. (1998). Nonlinear wavelet image processing: variational problems, compression, and noise removal through wavelet shrinkage. IEEE Transactions on Image Processing, 7(3), 319-335.

Dalmiya, S., Dasgupta, A. \& Kanti Datta, S. (2012). Application of Wavelet based K-means Algorithm in Mammogram Segmentation. International Journal of Computer Applications, 52(15), 15-19.

Daubechies, I. (1992). Ten Lectures on Wavelets, (1st ed.). CBMC-NSF Regional Conference Series in Applied Mathematics, 254-257.

Dheepa, G. \& Sukumaran, S. (2014). Hybrid Fusion Technique Using Dual Tree Complex Wavelet Transform for Satellite Remote Sensor Images. International Review on Computers and Software (IRECOS), 9(9), 1560-1567.

Eastman, J.R. (2001). Idrisi 32 Release 2: Guide to GIS and Image Processing, Volume 1. Clark Labs: Worcester, MA, USA.

Ergen, B. (2012). Signal and Image Denoising Using Waveñet Transform. In: Baleanu, D. (Ed.) Advances in wavelet Theory and Their Appplications in Engineeering, Physics and Technooogy, InTech Europe, Rijeka, Croatia. Pp. 495-514.

Fournier, N., Castro, G., Russo, C., \& Bria, O. (1997). Compresión de Imágenes fijas utilizando la Trasformada Wavelet. Congreso Argentino de Ciencias de la Compuntación CACIC 97, Universidad Nacional de La Plata, Argentina.

Gómez, E., Silva, E., Silva, D., \& Aponte, G. (2013). Selection of a mother wavelet for frequency analysis of transient electrical signals using WPD. Revista chilena de ingeniería, 2, 262-270. 
González, J. (2014). Transformadas Wavelet impacto fundamental en procesamiento de señales y compresión de imágenes. Master's Thesis, Technological University of Pereira, Colombia.

Haidu, I. (2016). What Is Technical Geography. Geographia Technica, 11(1), 1-5. DOI: 10.21163/GT_2016.111.01

Kingsbury, N. (2001). Complex wavelets for shift invariant analysis and filtering of signals. Appl. Comput. Harmon. Anal., 10(3), 234-253.

Lai, Y.K. \& Kuo, C.J. (2000). A Haar Wavelet Approach to Compressed Image Quality Measurement. Journal of Visual Communication and Image Representation, 11(1), 17-40.

Mallat, S. (1989). A theory for multi-resolution signal decomposition: The wavelet representation. IEEE Transaction on Pattern Analysis and Machine Intelligence, 7, 674-693.

Mancero, H., Morales, B., Tierra, A. (2017). Estimación Del Coeficiente De Hurst De Las Series Temporales De Tráfico Vehicular En Zonas Urbanas Por Rango_Reescalado. Revista Geoespacial, 14(1), 103-120.

Márquez, J. (2012). Ruido en datos, señales, imágenes. [Online] Available from www.academicos.ccadet.unam.mx/jorge.marquez/cursos/imagenes_neurobiomed/Ruido.pdf [Accessed October 2017].

Miano, J. (1999). Compressed Image File Formats: JPEG, PNG, GIF, XBM, BMP. Addison - Wesley, $112-113$.

Mohan, A. \& Poobal, S. (2017). Crack detection using image processing: A critical review and analysis. Alexandria Engineering Journal, 1-12.

NASA (2017) National Aeronautics and Space Administration. [Online] Avaible from www.landsat.gsfc.nasa.gov/landsat-5-2/ [Accessed March 2017].

Nieto, N. \& Orozco, D. (2008). The use of the discrete Wavelet transform in the reconstruction of sinusoidal signals. Scientia et Technica Año XIV, 38, 381-387.

Paz, J.E. (2001). Disminución del nivel de ruido en imágenes de Resonancia Magnética usando la Transformada Wavelet. La Habana, Cuba: Memorias II Congreso Latinoamericano de Ingeniería Biomédica.

Pérez A, La Mura, G., Piotrkowski, R. \& Serrano, E. (2002). Procesamiento No Lineal con Wavelet para la Eliminación del Ruido en Imágenes Planares de medicina nuclear. Revista Española de Medicina Nuclear, 1, 15-21.

Pipitone, C., Maltese, A., Dardanelli, G., Lo Brutto, M. \& La Loggia, G. (2018). Monitoring Water Surface and Level of a Reservoir Using Different Remote Sensing Approaches and Comparison with Dam Displacements Evaluated via GNSS. Remote Sensing, 10(71), 1-24.

Porwik, P. \& Lisowska, A. (2004). The Haar-Wavelet Transform in Digital Image Processing: Its Status and Achievements. Machine GRAPHICS \& VISION, 13(1,2), 79-98.

Rathinasamy, M., Bindhu, V.M., Adamowski, J., Narasimhan, B. \& Khosa, R. (2017). Investigation of the scaling characteristics of LANDSAT temperature and vegetation data: a wavelet-based approach. International Journal of Biometeorology, 61(10), 1709-1721

Raviraj, P. \& Sanavullah, M.Y. (2007). The Modified 2D-Haar Wavelet Transformation in Image Compression. Middle-East Journal of Scientific Research, 2(2), 73-78.

Shrivakshan, G.T. \& Chandrasekar, C. (2012). A Comparison of various Edge Detection Techniques used in Image Processing. IJCSI International Journal of Computer Science, 9(5), 269-276.

Talukder, K.H. \& Harada, K. (2007). Haar Wavelet Based Approach for Image Compression and Quality Assessment of Compressed Image. IAENG International Journal of Applied Mathematics, 36(1), 1-8.

Tierra, A. (2016). Nonlinear And Discontinuities Modeling Of Time Series Using Artificial Neural Network With Radial Basis Function. Geographia Technica, 11(2), 102-112. DOI: 10.21163/GT_2016.112.10

Villegas, J., Puetamán, G., \& Salazar, H. (2007). Modelo de error en imágenes comprimidas con wavelets. Revista de Ingeniería y Ciencias, 3, 111-133.

Weaver, J.B., Xu,Y., Healy, D.M. \& Cromwell, L.D. (1991). Filtering noise from images with wavelet transforms. Magnetic Resonance in Medicine, 21(2), 288-295. 